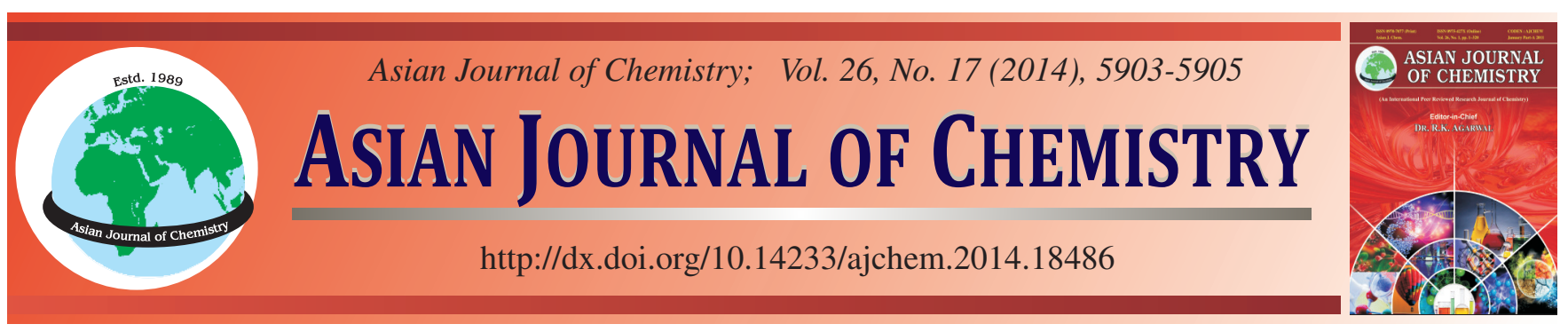

\title{
Development and Performances of Non-Phosphorus Corrosion and Scale Inhibitor $\dagger$
}

Yanmin Chen", Caixia Sun, Jinying Wu, Changshan Huang and Huiwu Xu

Energy Research Institute, Henan Academy of Science, Zhengzhou 450008, Henan Province, China

*Corresponding author: E-mail: yanminchen2011@163.com

One novel non-phosphorus multi-component composite water treatment agent was developed from polyepoxysuccinic acid, polyaspartic acid, polyacrylic acid and benzotriazole. The performances of scale and corrosion inhibition were evaluated by bubble experiments, rotary hanging-piece corrosion tests and electrochemical. The corrosion testing piece was characterized by SEM. The results showed that the new non-phosphorus composite water treatment agent had good performance of scale and corrosion inhibition. Further potentiodynamic polarization curves also indicated that the water treatment agent acted as a cathodic polarization-based suppression of mixed-type inhibitor.

Keywords: Non-phosphorus, Polyaspartic acid, Polyepoxysuccinic acid, Corrosion and scale inhibitor.

\section{INTRODUCTION}

With the rapid growth of the national economy and increasingly prominent contradiction of water shortages, water treatment technology for the purpose of water-saving is developing rapidly ${ }^{1,2}$. However, recent international and domestic water treatment chemicals are mostly phosphorus inhibitors, which have "red tides" of pollution defects resulted from eutrophication, algal blooms and water bacteria ${ }^{3}$. In this regard, the international community has proposed phosphorus banned or restricted measures.

Polyepoxysuccinic acid (PESA) and polyaspartic acid (PASP) are typical free-phosphorous water treatment agents in circulating cooling water system ${ }^{4-7}$. They are non-toxic, harmless, biocompatible and can be efficiently and stably degraded into water and carbon dioxide, which will not bring any damage to environments ${ }^{8-13}$. Polyacrylic acid (PAA) possesses good scale inhibition performance because of its strong role in dispersing dirt. Benzotriazole (BTA) is metal rust and corrosion inhibitor, which achieves the purpose of anti-corrosion due to the thin film adsorbed on the metal surface.

We studied the scale inhibition and corrosion inhibition on carbon steel of the composite PESA/PASP/PAA/BTA by the methods of bubble and weight-loss. Their corrosion inhibition behaviour is further characterized by polarization curve.

\section{EXPERIMENTAL}

Polyepoxysuccinic acid (PESA) and polyaspartic acid (PASP) were provided free of charge by Tianjin Wufutongtai chemical technology Co., Ltd., polyacrylic acid (PAA), benzotriazole (BTA), ethylene diamine tetraacetic acid (EDTA), calcein indicator, anhydrous ethanol and acetone were obtained from commercial sources. The properties of major reagents were shown in Table-1.

\begin{tabular}{lcccc}
\multicolumn{5}{c}{ TABLE-1 } \\
PHYSICAL PROPERTIES OF REAGENTS \\
\hline & PESA & PASP & PAA & BTA \\
\hline Appearance & Light & Red- & Light & White \\
& amber & brown & yellow & crystalline \\
& liquid & liquid & liquid & solid \\
Solid content $(\%)$ & 40 & 40 & 30.23 & 99 \\
Density $\left(\mathrm{g} / \mathrm{cm}^{3}\right)$ & 1.285 & 1.20 & 1.125 & - \\
$\mathrm{pH}(1 \%$ water solution $)$ & 10.12 & 9.80 & 2.81 & 5.50 \\
\hline
\end{tabular}

KZC-I scale analysis tester, RCC-I rotary hanging-piece corrosion instrument, CS2350 electrochemical workstation, JSM-6510 scanning electron microscopy (SEM) and BT224S electronic balance were purchased from Gaoyou city Qinyou instrument factory, Jiangdu city Jianhua instrument factory, Wuhan Corrtest instrument Co., Ltd., JEOL Ltd. and Sartorius scientific instrument (Beijing) Co., Ltd., respectively. 
Test water samples: The water samples were from running water and quality indices of the water were $\mathrm{pH}=7.0$, conductivity $=865 \mu \mathrm{s} \mathrm{cm}^{-1}, \mathrm{Ca}^{2+}=62.5 \mathrm{mg} \mathrm{L}^{-1}$, hardness $=2.4$ mmol L ${ }^{-1}$, alkalinity $=157.3 \mathrm{mg} \mathrm{L}^{-1}$.

\section{Methods}

Scale inhibition: The scale inhibition of composite water treatment agent was evaluated by using bubble method, which referenced HG/T2024-91. The experiment conditions including water bath temperature, air flow and test time were $60{ }^{\circ} \mathrm{C}$, $80 \mathrm{~L} / \mathrm{h}$ and $6 \mathrm{~h}$, respectively. The scale inhibition rate formulae (eqns. 1 and 2) were as followed:

$$
\chi=\frac{\mathrm{C}_{\mathrm{Ca}_{(1)}^{2+}}-\mathrm{C}_{\mathrm{Ca}_{(0)}^{2+}}}{\mathrm{C}_{\mathrm{Ca}_{(2)}^{2+}}-\mathrm{C}_{\mathrm{Ca}_{(0)}^{2+}}} \times 100 \%
$$

$\mathrm{C}_{\mathrm{Ca}_{(2)}^{2+}}$ : The $\mathrm{Ca}^{2+}$ concentration before the test in the blank water sample, $\mathrm{mg} / \mathrm{L} ; \mathrm{C}_{\mathrm{Ca}_{(1)}^{2+}}$ : the $\mathrm{Ca}^{2+}$ concentration after the test with water treatment agent, mg/L; $\mathrm{C}_{\mathrm{Ca}_{(0)}^{2+}}$ : the $\mathrm{Ca}^{2+}$ concentration after the test without water treatment agent, $\mathrm{mg} / \mathrm{L}$.

$$
\mathrm{C}_{\mathrm{Ca}^{2+}}=\frac{\mathrm{V} \times \mathrm{C} \times 40.08}{25.00} \times 1000=1603 \times \mathrm{V} \times \mathrm{C}
$$

$\mathrm{V}$ : the volume of EDTA standard solution, $\mathrm{mL} ; \mathrm{C}$ : the concentration of EDTA standard solution, mol/L; 25.00: the sample volume, $\mathrm{mL}$; 40.08: calcium ion mass $(\mathrm{mg})$ corresponding to $1.00 \mathrm{~mL}$ EDTA standard solution $\left(\mathrm{C}_{\mathrm{EDTA}}=1.000 \mathrm{~mol} / \mathrm{L}\right)$.

Corrosion inhibition: The corrosion inhibition of composite water treatment agent was evaluated by using rotary hanging-piece experiment, which referenced GB/T181752000. The experiment conditions including water temperature, speed and test time were $45^{\circ} \mathrm{C}, 100 \mathrm{rpm}$ and $72 \mathrm{~h}$, respectively. The corrosion rate formulae (eqns. 3 and 4 ) were as followed:

$$
\eta(\%)=\frac{X_{0}-X_{1}}{X_{0}} \times 100
$$

$\mathrm{X}_{1}$ : The corrosion rate with water treatment agent; $\mathrm{X}_{0}$ : the corrosion rate without water treatment agent.

$$
X=\frac{8760 \times 10 \times\left(\mathrm{m}-\mathrm{m}_{0}\right)}{\mathrm{s} \cdot \rho \cdot \mathrm{t}}
$$

$\mathrm{m}$ : The value of specimen mass loss, $\mathrm{g} ; \mathrm{m}_{0}$ : the average value of specimen pickling mass loss, $g$; $s$ : the specimen surface area, $\mathrm{cm}^{2} ; \rho$ : the specimen density, $\mathrm{g} / \mathrm{cm}^{3} ; \mathrm{t}$ : test time, h; 8760: a number of hours corresponding to a year, h/a.

SEM morphology analysis: The corrosion behaviour of carbon steel was obtained through JSM-6510 scanning electron microscopy (SEM). The carbon steel specimen was pasted on the sample stage with conductive adhesive and then it was observed at $15 \mathrm{kV}$ accelerating voltage and $\times 1000$ magnification.

Electrochemical experiment: The classical three-electrode system, which auxiliary electrode, reference electrode and working electrode were platinum electrode, saturated calomel electrode and A3 carbon steel (the total surface area was $1.0 \mathrm{~cm}^{2}$ ), respectively, was used to measure polarization curves by potentiodynamic scanning at room temperature. The polarized scanning range and scanning rate were $\mathrm{E}_{\text {corr }}= \pm 0.3$ $\mathrm{V}$ and $0.5 \mathrm{mV} / \mathrm{s}$ and test water was running water. Before testing, working electrode was polished by $800-1200 \#$ abrasive paper, cleaned by distilled water, anhydrous ethanol and acetone, then dry naturally and immersed in the electrolyte $0.5 \mathrm{~h}$.

\section{RESULTS AND DISCUSSION}

Corrosion and scale inhibitor prescription: Based on a lot of preliminary experiments, the material compositions and the concentration range of materials of a new non-phosphorus scale and corrosion inhibitor were initially identified ${ }^{4-6,14}$. The materials contained PESP (6-10 mg/L), PASP (8-12 mg/L), PAA (6-10 mg/L) and BTA (4-6 mg/L).

As shown in Table-2, when the prescription was $\mathrm{A}_{2} \mathrm{~B}_{3} \mathrm{C}_{2} \mathrm{D}_{2}$,

\begin{tabular}{|c|c|c|c|c|c|}
\hline \multicolumn{6}{|c|}{$\begin{array}{c}\text { TABLE-2 } \\
\text { DESIGN OF ORTHOGONAL EXPERIMENT } \\
\text { L }_{9}\left(3^{4}\right) \text { AND EXPERIMENT RESULTS }\end{array}$} \\
\hline No. & $\begin{array}{c}\text { (A) } \\
\text { PESA } \\
\left(\mathrm{mg} \mathrm{L}^{-1}\right)\end{array}$ & $\begin{array}{c}\text { (B) } \\
\text { PASP } \\
\left(\mathrm{mg} \mathrm{L}^{-1}\right)\end{array}$ & $\begin{array}{c}\text { (C) } \\
\text { PAA } \\
\left(\mathrm{mg} \mathrm{L}^{-1}\right)\end{array}$ & $\begin{array}{c}\text { (D) } \\
\text { BTA } \\
\left(\mathrm{mg} \mathrm{L}^{-1}\right)\end{array}$ & $\begin{array}{c}\text { Corrosion } \\
\text { rates }\left(\mathrm{mm} \mathrm{a}^{-1}\right)\end{array}$ \\
\hline 1 & 6 & 8 & 6 & 4 & 0.1211 \\
\hline 2 & 6 & 10 & 8 & 5 & 0.1104 \\
\hline 3 & 6 & 12 & 10 & 6 & 0.0921 \\
\hline 4 & 8 & 8 & 6 & 6 & 0.0846 \\
\hline 5 & 8 & 10 & 10 & 4 & 0.0697 \\
\hline 6 & 8 & 12 & 8 & 5 & 0.0581 \\
\hline 7 & 10 & 8 & 10 & 5 & 0.0675 \\
\hline 8 & 10 & 10 & 6 & 6 & 0.0777 \\
\hline 9 & 10 & 12 & 8 & 4 & 0.0853 \\
\hline
\end{tabular}
the composite agent had the best corrosion inhibition performance for carbon steel, so the optimal concentration ratios of four materials were PESA/PASP/PAA/BTA $=8: 12: 8: 5^{15}$.

Corrosion inhibition performance: According to above concentration ratio, upon increasing of the composite agent concentration from 15-55 mg/L, changes of corrosion inhibition rates for A3 carbon steel were shown in Fig. 1. The corrosion inhibition rates became lager during the raising agent concentrations and stable at the concentration of $45 \mathrm{mg} / \mathrm{L}$ with $89 \%$ corrosion inhibition rate. These facts indicate that the water treatment agent has good corrosion inhibition performance for A3 carbon steel.

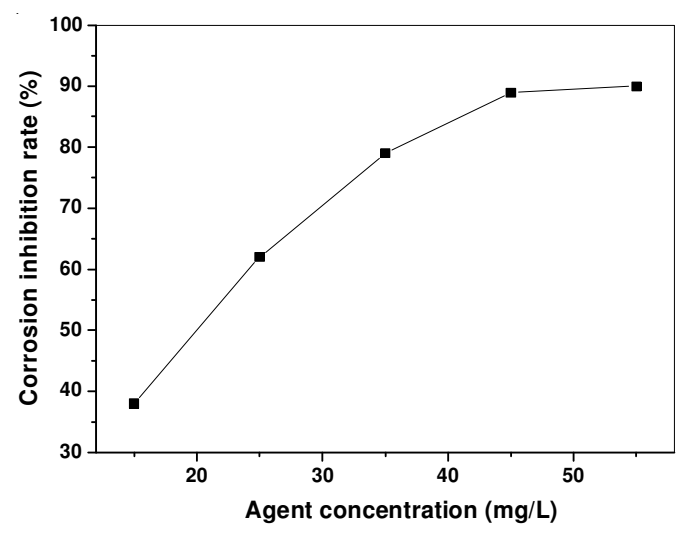

Fig. 1. Changes of corrosion inhibition rates for A3 carbon steel upon increasing composite agent concentrations from $15-55 \mathrm{mg} / \mathrm{L}$ 
Scale inhibition performance: According to bubble method, the scale inhibition rate of composite water treatment agent at the concentration of $40 \mathrm{mg} / \mathrm{L}$ was measured by dropwise standard EDTA solution $\left(\mathrm{C}_{\mathrm{EDTA}}=0.01 \mathrm{~mol} / \mathrm{L}\right)$ to $25 \mathrm{~mL}$ of water sample. The results indicate that the composite agent has excellent scale inhibition performance with $93 \%$ scale inhibition rate, which calculated from eqns. 1 and 2.

SEM analysis: After rotary hanging-piece experiment, two A3 carbon steel specimens, which from blank and corrosion and scale inhibitor solution, respectively, were SEM morphology analyzed (Fig. 2). Fig. 2(a) shows that the blank specimen was corroded seriously and its surface appears much pitting corrosion and gap, while the other specimen has complete and smooth carbon steel surface [Fig. 2(b)]. It is apparent that carbon steel can be well protected from corrosion in the presence of scale and corrosion inhibitor.
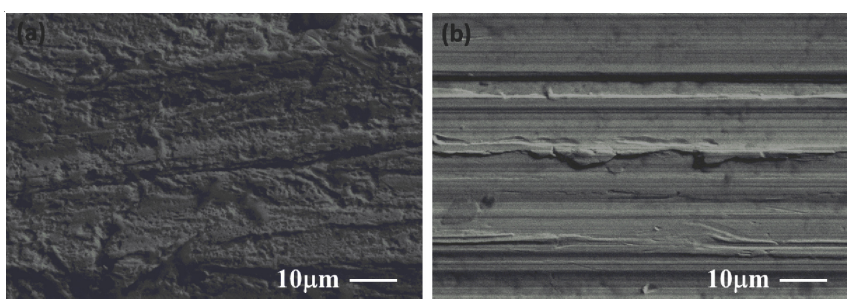

Fig. 2. SEM micrographs of A3 carbon steel after testing

Polarization curves test: The polarization curves of carbon steel in the absence (a) and the presence (b) of corrosion and scale inhibitor were shown in Fig. 3. The self-corrosion potential and current were $\mathrm{E}_{0}=-0.30 \mathrm{~V}, \mathrm{I}_{0}=1.15 \times 10^{-8} \mathrm{Amp}$ $\mathrm{cm}^{-2}$ and $\mathrm{E}_{0}=-0.34 \mathrm{~V}, \mathrm{I}_{0}=1.91 \times 10^{-8} \mathrm{Amp} \mathrm{cm}^{-2}$ in the condition of adding agent or not, respectively. After adding agent, the polarization curve of carbon steel underwent a positive move because of the increase of self-corrosion potential. Moreover, the cathodic polarization curve slope decreased obviously and anodic polarization curve slope increased a little. It is clear from the discussion above that the composite scale and corrosion inhibitor is cathodic polarization-based suppression of mixed-type inhibitor.

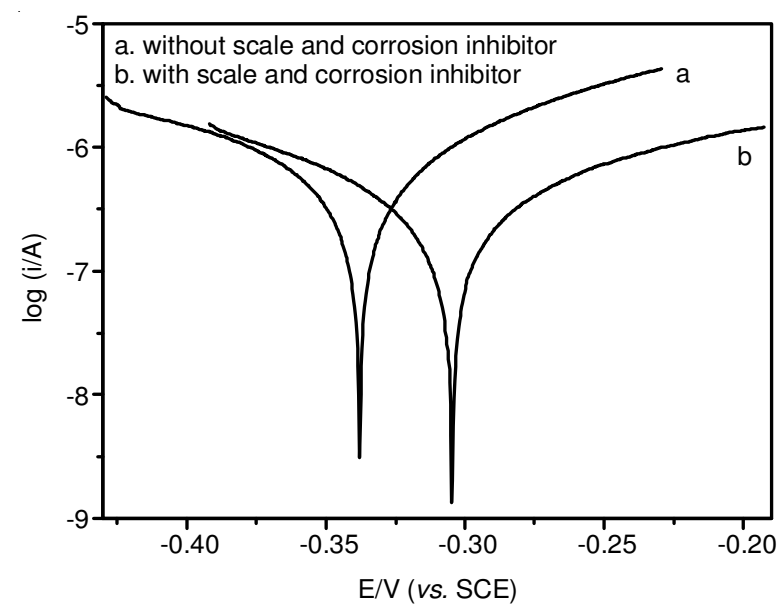

Fig. 3. Potentiodynamic polarization curves of carbon steel with and without composite scale and corrosion inhibitor
Some common corrosion and scale inhibitors, such as HEDP-PAA-HPMA-BTA composite, STPP-PAAS-EDTMPMBT composite and SHMP-HPMA-HEDP- $\mathrm{ZnSO}_{4}$ composite, have good corrosion inhibition and scale inhibition performances, but they are containing phosphorus chemicals and can't be decomposed well, so they can pose an environmental hazard. However, there are no such problems in our new chemical formulation.

\section{Conclusion}

The concentration ratios of four materials of non-phosphorus multi-component composite scale and corrosion inhibitor are PESA/PASP/PAA/BTA $=8: 12: 8: 5$. It possesses excellent scale inhibition and corrosion inhibition performance with scale inhibition rate $93 \%$ and corrosion inhibition rate $89 \%$ at the concentration of $45 \mathrm{mg} / \mathrm{L}$. The SEM morphology analysis results show that the scale and corrosion inhibitor has good performance to protect equipments and piping in the industrial cooling water. Potentiodynamic scanning polarization curves indicate that the composite water treatment agent is a cathodic polarization-based suppression of mixed-type inhibitor.

\section{ACKNOWLEDGEMENTS}

This work was financially supported by the Henan Province Key Project of Science and Technology (122102210259).

\section{REFERENCES}

1. X. Wang, Z.F. Liu, Y.H. Gao and Z. Liu, Ind. Water Treat., 33, 26 (2013).

2. M.A. Quraishi, A. Singh, V.K. Singh, D.K. Yadav and A.K. Singh, Mater. Chem. Phys., 122, 114 (2010).

3. W. Liu, S.M. Chen, N. Xiong, H. Ming and X.P. Ma, Corros. Prot. Petrochem. Ind., 27, 5 (2010).

4. Y.M. Chen, C.X. Sun, M. Zhang, M. Chen, H.W. Xu, R.J. Liu, Y.S. Cheng, J.Y. Wu and C.S. Huang, Clean World, 29, 15 (2013).

5. Y.M. Chen, C.X. Sun, H.W. Xu, J.Y. Wu and C.S. Huang, Adv. Mater. Res., 881-883, 604 (2014).

6. Y.M. Chen, C.X. Sun, M. Chen, J.Y. Wu and H.W. Xu, Henan Sci., 31, 1159 (2013).

7. H.P. Wang, Q. Wu, C.M. Li and N. Gu, Mater. Corros., 64, 347 (2013).

8. R.K. Vagapov, V.S. Bizyaeva and V.I. Kichigin, Prot. Met., 43, 643 (2007).

9. B. Qian, J. Wang, M. Zheng and B.R. Hou, Corros. Sci., 75, 184 (2013).

10. Z.Y. Liu, Y.H. Sun, X.H. Zhou, T. Wu, Y. Tian and Y.Z. Wang, J. Environ. Sci. (China), 23, S153 (2011).

11. D. Liu, W.B. Dong, F.T. Li, F. Hui and J. Lédion, Desalination, 304, 1 (2012).

12. Y.H. Sun, W.H. Xiang and Y. Wang, J. Environ. Sci. (China), 21, S73 (2009).

13. Y. Wang, H.X. Feng, T. Zhang and J.L. Zhu, Water Purif. Technol., 27, 62 (2008).

14. Y.M. Chen, C.X. Sun, Y.S. Cheng, M. Zhang and M. Chen, Appl. Chem. Ind., 43, 647 (2014).

15. X.J. Hu, Z.F. Liu, X.L. Wu and Y.H. Gao, Technol. Water Treat., 36, 38 (2010). 